\title{
Fabrication and Evaluation of Non-Medicated Jellies of Carrot, Beetroot and Papaya
}

\section{Jyothi Sri S, Sahoo NK*, Kusuma D and Uma Shankar CH}

Department of Pharmaceutical Sciences, MLR Institute of Pharmacy, India

*Corresponding author: Nalini KS, MLR Institute of Pharmacy, Dundigal, Medchal, Hyderabad, Telangana, India, Tel: 9550741536; Email: sahoo.nalini@gmail.com

\section{Research Article}

Volume 3 Issue 4

Received Date: October 09, 2019

Published Date: October 31, 2019

DOI: $10.23880 /$ oajpr-16000187

\section{Abstract}

The current study is conducted for processing of jelly from carrot, beet root and papaya juices at different stages of extraction. Sensory attributes and storage studies of the jellies were also evaluated. The fresh and fully mature carrots, beet root, papaya were used for this experiment. The Juices of all different fruits were collected by extraction process. In this research Gelatin is used as a gelling agent, sucrose as a sweetening agent and citric acid as a salivating agent. Chemical characteristics such as moisture, ash, acidity, vitamin C, sugar and total soluble solids (TSS) of edible fruits, juice and jellies were determined. With respect to chemical composition initially extracted juice was found better than the other two. The jelly from composite of extractions juice was found better than other jellies as per chemical composition and sensory evaluation. On the basis of sensory evaluation the carrot, beet root, papaya jellies prepared from different extractions of juice considering, smell and taste, color, texture and overall acceptability the jelly prepared from composite of extractions of juice was more acceptable than others. Storage study was conducted on the jellies for 60 days at room temperature $\left(23-30^{\circ} \mathrm{C}\right)$ and relative humidity 80 to $85 \%$. It was observed that TSS, $\mathrm{pH}$ and acidity of jelly did not show any remarkable changes. Color and flavor was acceptable up to 60 days but after 70 days the color and flavor of jellies were changed due to fungal growth and incipient spoilage.

Keywords: Carrot, Beet root, Papaya, Relative humidity, Vitamin C, Extraction

\section{Introduction}

The medical compositions for oral administration listed in the general medical preparations like tablets, capsules, pills, powders, liquid, syrup, and the like. Such dosage forms are not easily taken by patients of advanced age, particularly patients with dysphagia. Among these, liquid and syrup preparations are easily taken by them compared with the other dosage forms. However, because of liquid, there are problems to be overcome, when formulating into dosage forms, such as masking of bitterness of effective components, their dispersibility and stability [1].

Jellies are semisolid to thick viscous fluids that consist of sub microscopic particles in a somewhat rigid or plastic vehicle. They are transparent or translucent, non-greasy and mucilage type products [2]. The jelly dosage form can be swallowed easily without water and are soft and smooth. Edible jellied compositions include sweet jellies 


\section{Open Access Journal of Pharmaceutical Research}

used in food industry, which are prepared usually using as a base one or two or more of gelatin, pectin, Xanthum gum, carrageenan, locust bean gum and the like. Their appearances are secured usually for about one year under preservation at room temperature or in cool place [3]. However, none of them can keep preservation stability in terms of $\mathrm{pH}$ and the contents of the components at the medical level tests. They are prepared from natural gums such as Tragacanth, acacia, pectin or some synthetic derivatives of natural substances, like methyl cellulose and sodium car boxy methyl cellulose. These are similar to mucilage such that they are prepared from gums, but they differ from mucilage by having jelly like consistency. There are different types of jellies such as Medicated jellies, Non- medicated jellies, Lubricating Jellies, Miscellaneous Jellies.

This presents research in the field of natural jellies. The aim of this study was to produce of beetroot juice blends with carrot and papaya juice as healthy beverage and new product as a reduction in BP. Furthermore, the concept of natural jellies was reviewed and discussed.

The work is aimed to develop and evaluate oral nonmedicated jelly of carrot, beetroot and papaya. To ensure satisfactory with the help of sweeting agents, gelling agents and thereby sensory analysis.

\section{Carrot}

Carrot juice produced from carrots is often consumed as a health drink. It has particularly high content of $\beta$ carotene, a source of vitamin A, but it is also high in B complex vitamins and many minerals including calcium, copper, magnesium, potassium, phosphorus, and iron. They are scientifically classified as Daucus carota and categorized as a root vegetable. It belongs to family Umbelliferae (Figure 1) [4].

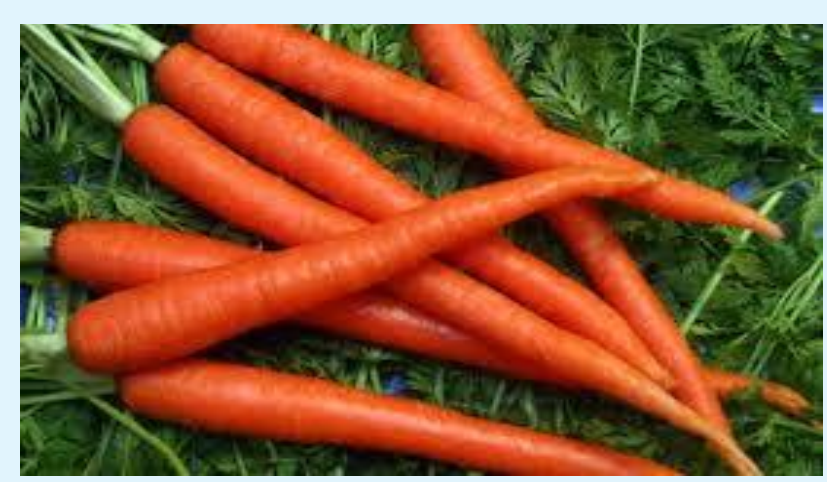

Figure 1: Cultivated carrots.

\section{Beetroot}

It is one of several of the cultivated varieties of Beta vulgaris grown for their edible taproots and their leaves (called beet greens). These varieties have been classified as B. vulgaris subsp. vulgaris Conditiva Group. It belongs to family Chenopodiaceae. Recent report indicates that beet root extract possesses anti-hypertensive, hypoglycemic, anti-oxidant, anti-inflammatory, and hepatic protective activity (Figure 2) [5].

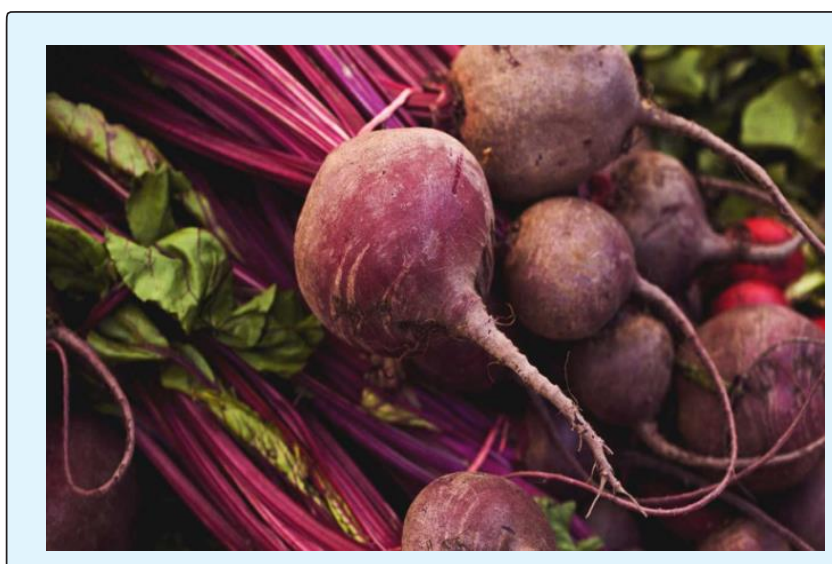

Figure 2: Cultivated beet root.

\section{Papaya}

Papaya (Carica papaya L.) an important fruit of tropical and sub-tropical regions of the world belongs to family caricaceae and also known as papita, pawpaw and true melon [6]. It is used in prevention diseases like Asthma prevention, Cancer, Bone health, Diabetes, Digestion, Heart disease, Inflammation, Skin and healing and Hair health (Figure 3).

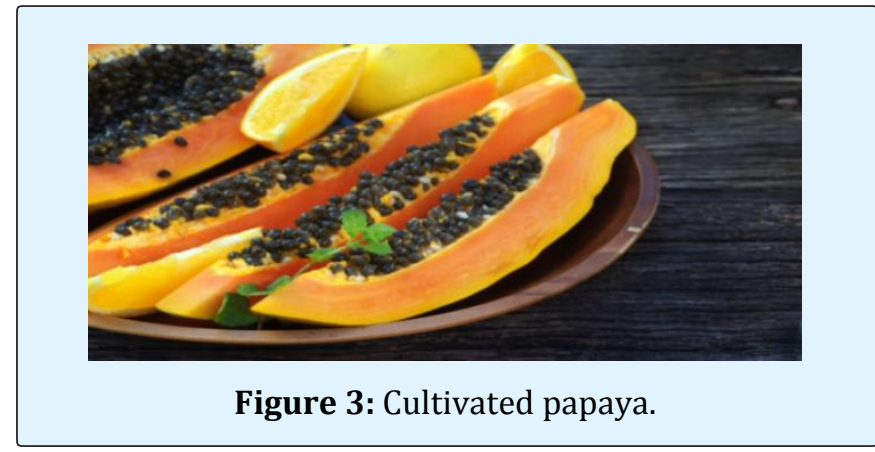

\section{Materials and Methods}

\section{Materials}

Carrot (Vitamin A), beet root (Vitamin A, C, B6), papaya (Vitamin C), Gelatin (Gelling agent), Sucrose 


\section{Open Access Journal of Pharmaceutical Research}

(Sweetening agent) procured from Metro super market. Citric acid (Salivating agent) procured from S.D. Fine chemicals, Mumbai

\section{Methods}

Preparation of carrot extract: Cleaned and graded carrots were peeled with peeler and then size reduction operations were carried out on them. Then all the carrots shreds were added in 1.5 times water and then boiled for 15-20 minutes. The carrots extract was then strained off and collected for further use. The boiled slices were then strained using muslin cloth to obtain carrots juice extract and then again filtered and added to the drained juice to obtain clear juice extract.

Preparation of beet root extract: Cleaned and graded beet roots were peeled with peeler and then size reduction operations were carried out on them. Then all the beet root shreds were added in 1.5 times water and then boiled for 15-20 minutes. The beet extract was then strained off and collected for further use. The boiled slices were then strained using muslin cloth to obtain beet root juice (BRJ) extract and then again filtered and added to the drained juice to obtain clear juice extract [7].

Preparation of papaya extract: Cleaned and graded beet roots were peeled with peeler and then size reduction operations were carried out on them. Then all the papaya shreds were added in 1.5 times water and then boiled for 15-20 minutes. The papaya extract was then strained off and collected for further use. The boiled slices were then strained using muslin cloth to obtain papaya juice extract and then again filtered and added to the drained juice to obtain clear juice extract [8].

Preparation of carrot, beet root and papaya jelly: The carrot, beet root, papaya mixed fruit jelly were prepared according to the standardized procedure. The jelly was prepared from the extracted carrot, beet root, papaya juice by power operated juice extractor, adjusting its soluble solid and acidity as per FPO specifications for jelly by mixing the juice with required quantity of sugar syrup prepared from sugar and added the citric acid and gelatin during boiling. The prepared jelly was filled into jar leaving a head space of 2.5 to $3.0 \mathrm{~cm}$ and capping was done. Labeled jars were stored at room temperature. Sample containing three of fruit extract proportion viz.25:20:50, 25:50:25, 50:25:20 of carrot, beet root, papaya, were prepared and evaluation by sensory panel. The samples were prepared and storage studies were conducted. The jars were labeled and stored at room temperature up to 90 days to determine the physicochemical and sensory quality attributes of mixed fruit jelly. Total soluble solids (TSS) were determined using hand refractrometer. The color was measured in terms of optical density. Sensory evaluation for various attributes was done on the hedonic scale using prescribed performed by sensory panel [9].

\section{Evaluation Studies}

\section{Physico-Chemical Analysis}

Biochemical quality and organoleptic evaluation of papaya fruit bar was carried out at zero, 30, 60 and 90 days after storage. Two samples per treatment were subjected to physicochemical analysis. The parameters such as TSS, $\mathrm{pH}$, total sugars, reducing sugars, titrable acidity, ascorbic acid and overall acceptability were analyzed by the methods. Moisture content was determined on fresh weight basis. Protein content and total carotenoids in papaya guava bar sample was prepared respectively [10].

Alcohol test: One teaspoon of strained juice extract was taken in a glass beaker and cooled and to that 3 teaspoon of methylated spirit was poured gently down on the side of beaker, which was shaken and allowed to stand for few minutes. As the extract was poor in pectin, numerous small clots were seen, so half the amount of sugar was added with respect to the amount of extract, i.e. Juice extract: Sugar is 1:0.5 [11].

pH: The $\mathrm{pH}$ of the treated juice samples was determined using a digital $\mathrm{pH}$ meter (model PHs-2f, USA). The $\mathrm{pH}$ meter was calibrated using buffer solution at $\mathrm{pH} 4.0$ and 7.0. Ten $(10 \mathrm{ml})$ of each juice sample was measured into a $10 \mathrm{ml}$ beaker. The electrode of the $\mathrm{pH}$ meter was placed into the beaker containing juice samples and the $\mathrm{pH}$ was read off on the LCD screen after sufficient time was allowed for stabilization [12].

Total solid: The total solid content of the treated juice samples was determined using the air oven method. Aluminium dishes were washed; dried in the oven for $10 \mathrm{~min}$ at $30^{\circ} \mathrm{C}$ and kept in the desiccator to cool, after which their weights were taken. Three grams (3g) of the treated juice samples were weighed into the dishes and the weight of the dish plus samples was taken. The dishes were placed in the oven for $1 \mathrm{~h}$ at $105^{\circ} \mathrm{C}$. The dishes were removed after cooling and total solid content was calculated.

Moisture content: The prepared jelly were stored in desiccator and observed for every 10 days.

Sensory Analysis Protocol 9-point hedonic scale was used for analyzing different sensory attributes like appearance, color, flavor, texture and overall acceptability by a panel of 10 trained members having experience in 


\section{Open Access Journal of Pharmaceutical Research}

sensory evaluation of fruits and vegetable products. Average scores were calculated accordingly [13].

\section{Results and Discussion}

\section{Preparation of Jellies (Figure 4-9)}
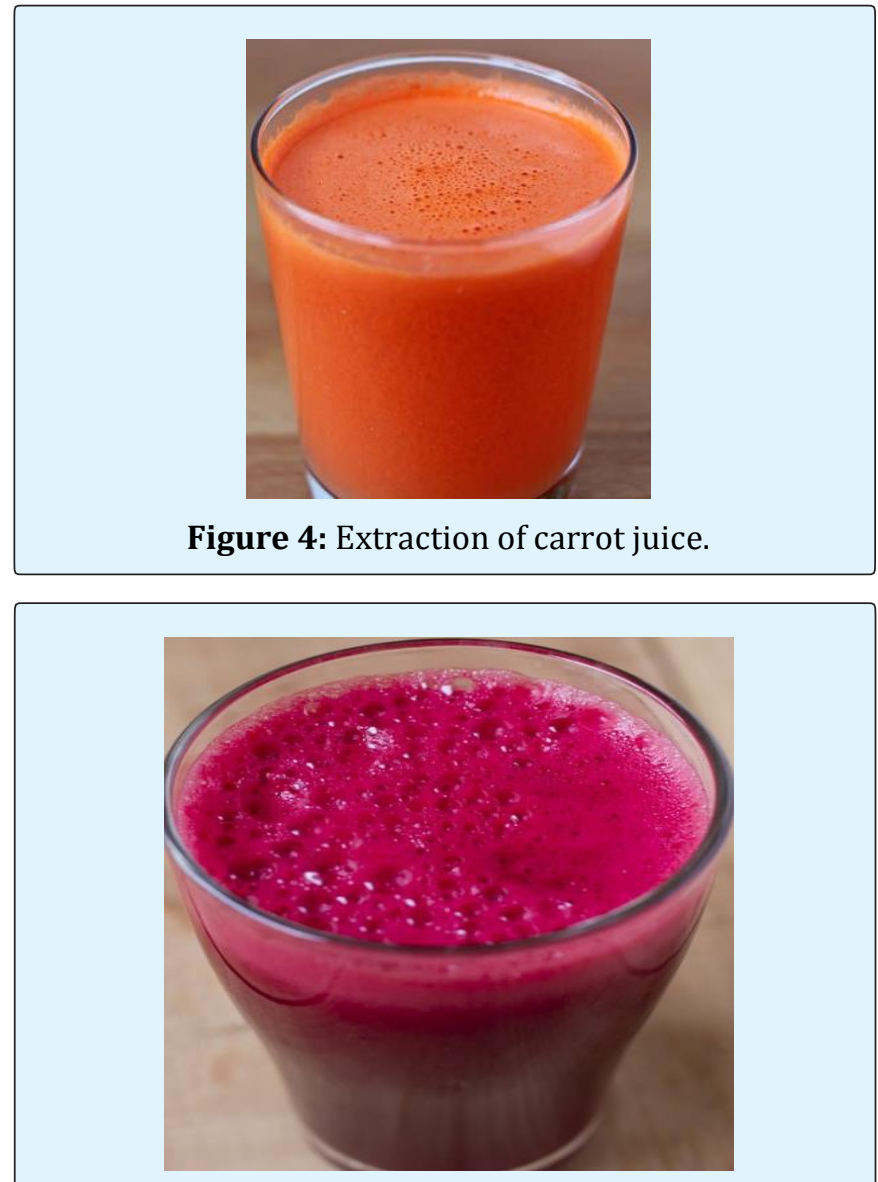

Figure 5: Extraction of Beet root juice.

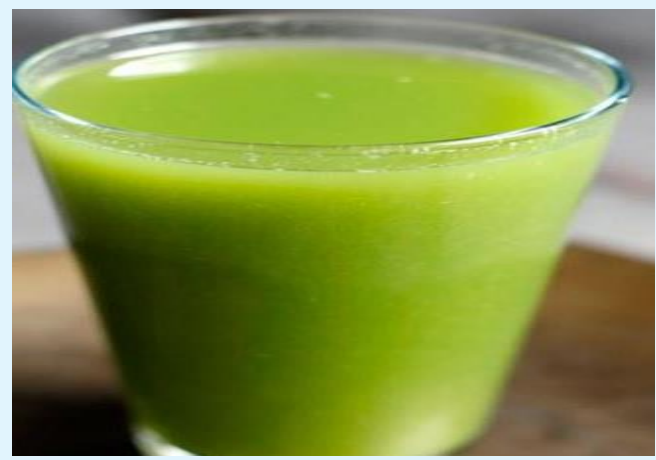

Figure 6: Extraction of Papaya juice.
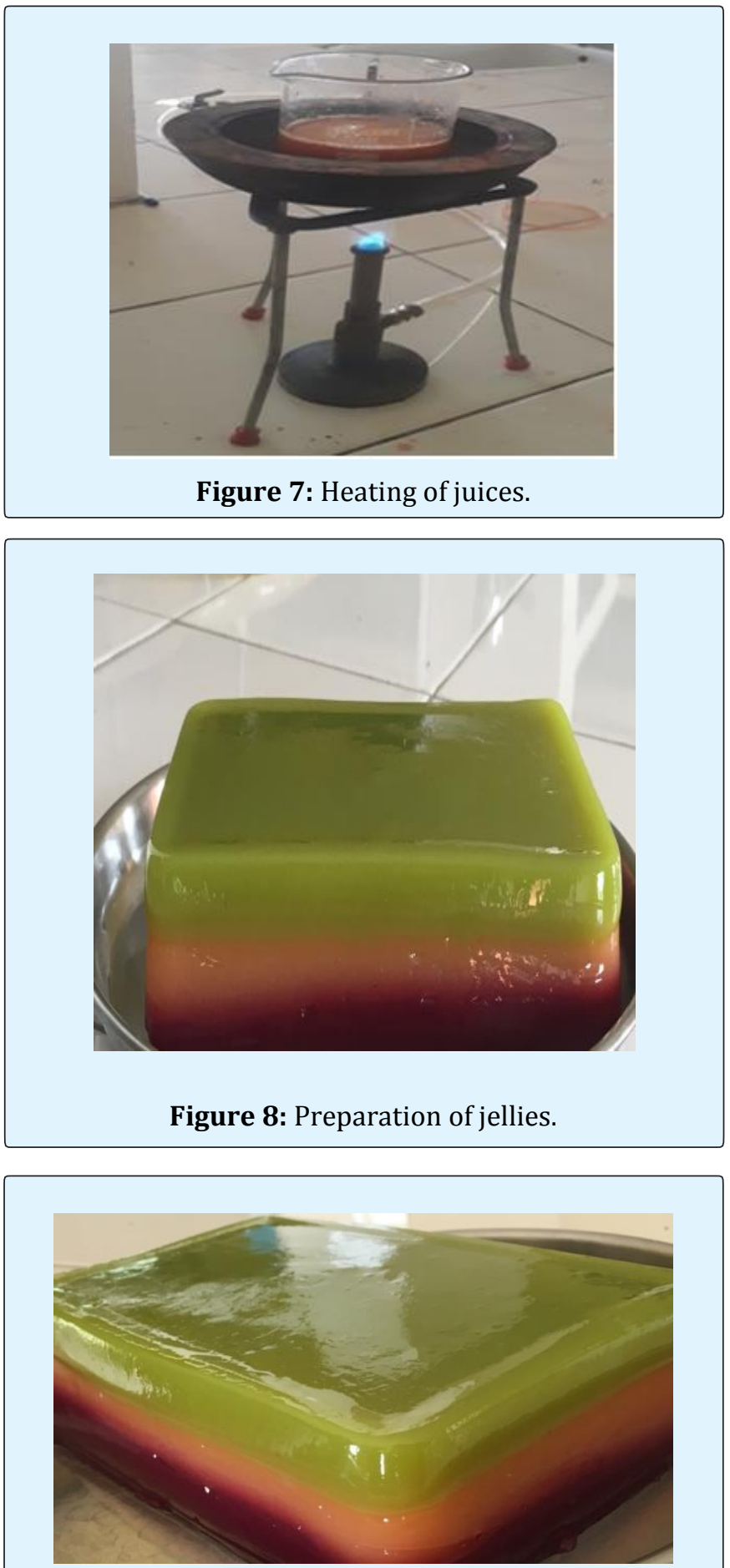

Figure 9: Preparation of jellies. 


\section{Open Access Journal of Pharmaceutical Research}

\begin{tabular}{|c|c|c|c|c|c|c|}
\hline Samples & Carrot(ml) & Beet root(ml) & Papaya(ml) & Sugar(gm.) & Gelatin (gm.) & Citric acid(gm.) \\
\hline A & 25 & 20 & 50 & 200 & 5 & 0.5 \\
\hline B & 25 & 50 & 25 & 244 & 10 & 2.5 \\
\hline C & 50 & 25 & 20 & 225 & 8 & 5 \\
\hline
\end{tabular}

Table 1: Formulation of jellies.

\section{Evaluation of Jellies}

\section{Alcohol Test}

One teaspoon of strained juice extract was taken in a glass beaker and cooled and to that 3 teaspoon of methylated spirit was poured gently down on the side of beaker, which was shaken and allowed to stand for few minutes. As the extract was poor in gelatin, numerous small clots were seen, so half the amount of sugar was added with respect to the amount of extract. Here we can observe for jellies such as Avoid prolonged cooking since it destroyed coagulation property of pectin. During boiling of mixture scum forms over the surface, if not removed it results in the formation of cloudy jelly. Care should be taken during pouring.

\section{Moisture Content}

The highest moisture content (15.98\%) in fruit jelly at zero days of storage was recorded in sample B. The lowest moisture content (15.22\%) was recorded in sample C. at zero days of storage furnished in Table 1. At 15 days of storage, highest moisture content (15.96\%) was recorded in sample B and the lowest moisture content $(15.21 \%)$ was recorded in sample C. At 30 days storage highest moisture content (15.94\%) was recorded in sample B and lowest moisture content is found in $(15.19 \%)$ in sample C. At 45 days the highest moisture content was recorded in sample B $(15.92 \%)$ and lowest moisture content recorded in sample C (15.15\%).At 60 days the highest moisture content recorded in sample B (15.89\%) and lowest moisture content in sample C $(15.10 \%)$. A close perusal of data indicates that there was slight decrease in moisture content of carrot, beetroot and papaya jelly with the advancement of storage period irrespective of blending ratios (Table 1). There was a slight decrease in moisture content may be due to evaporation of water from jelly during storage (Figure $10)$.

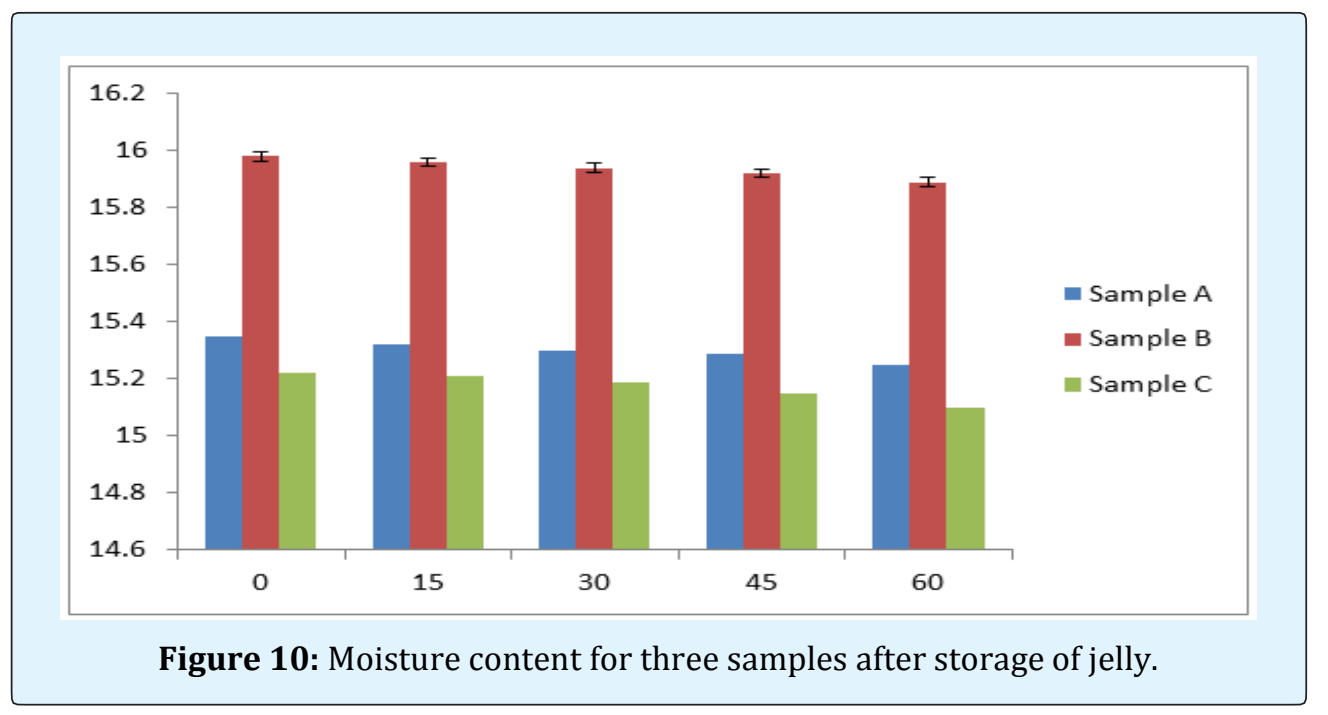

\section{pH}

There were significant differences among treatments for $\mathrm{pH}$ in jelly at $0,15,30,45$ and 60 days of storage (Table 2). The $\mathrm{pH}$ values in jelly ranged from 3.48 (sample
B) to 3.62 (sample A). Among the treatments highest $\mathrm{pH}$ of 3.62 was recorded in jelly of sample B, There was a negligible increase in $\mathrm{pH}$ of jelly was noticed in all the treatments, which might be due to formation of free acids and hydrolysis of gelatin (Figure 11). 


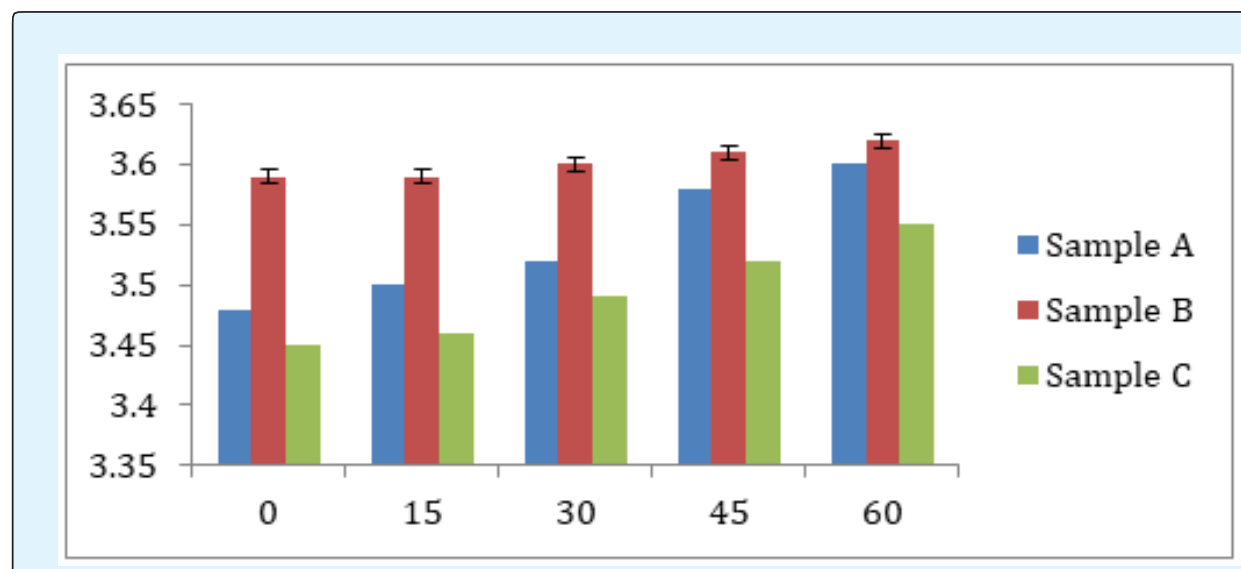

Figure 11: $\mathrm{pH}$ for three samples after storage of jelly.

\section{Total Sugars}

Total sugars in fruit bar made with different blending ratios of jelly at $0,15,30,45$ and 60 days of storage ranged from $69.32 \%$ (sample B) to $66.15 \%$ (sample C).
The slight decrease in total sugars per cent during storage might be due to of inversion of sugars to monosaccharide by acid hydrolysis (Figure 12).

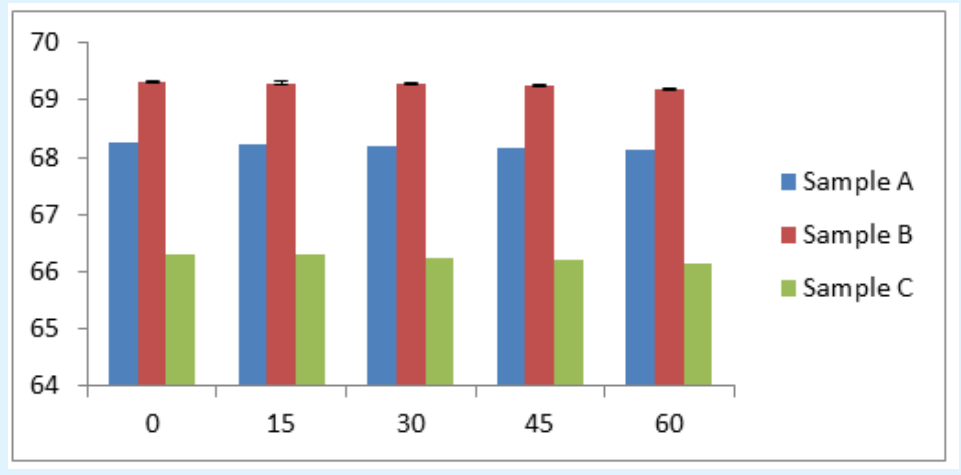

Figure 12: Total sugars for three samples after storage of jelly.

\begin{tabular}{|c|c|c|c|c|c|c|c|c|c|c|c|c|c|c|c|}
\hline \multirow{2}{*}{ Samples and evaluation of jellies } & \multicolumn{4}{|c|}{$\mathbf{A}$} & \multicolumn{4}{|c|}{ C } & \multicolumn{4}{|c|}{} \\
\cline { 2 - 14 } & 0 & 15 & 30 & 45 & 60 & 0 & 15 & 30 & 45 & 60 & 0 & 15 & 30 & 45 & 60 \\
\hline Moisture content & 15.4 & 15.3 & 15.3 & 15.3 & 15.3 & 16 & 16 & 15.9 & 15.9 & 15.9 & 15.2 & 15.2 & 15.2 & 15.2 & 15.1 \\
\hline $\mathbf{p H}$ & 3.48 & 3.5 & 3.52 & 3.58 & 3.6 & 3.59 & 3.59 & 3.6 & 3.61 & 3.62 & 3.45 & 3.46 & 3.49 & 3.52 & 3.55 \\
\hline Total sugars & 68.3 & 68.2 & 68.2 & 68.2 & 68.1 & 69.3 & 69.3 & 69.3 & 69.3 & 69.2 & 66.3 & 66.3 & 66.3 & 66.2 & 66.2 \\
\hline
\end{tabular}

Table 2: Evaluation tests for formulated jellies.

\section{Sensory Evaluation:}

It was observed that Sample A, Sample B and Sample C had same average scores but was lower than Sample A which had an maximum color score of 7.2, Similar trend was seen in other attributes like texture and flavour.
Although there was a marked difference in the scores of the taste attributes, highest score was obtained by sample B. Overall; all the sensory attributes indicated higher average score of B. So sample B was selected for further formulation (Figure 13-16, Table 3). 


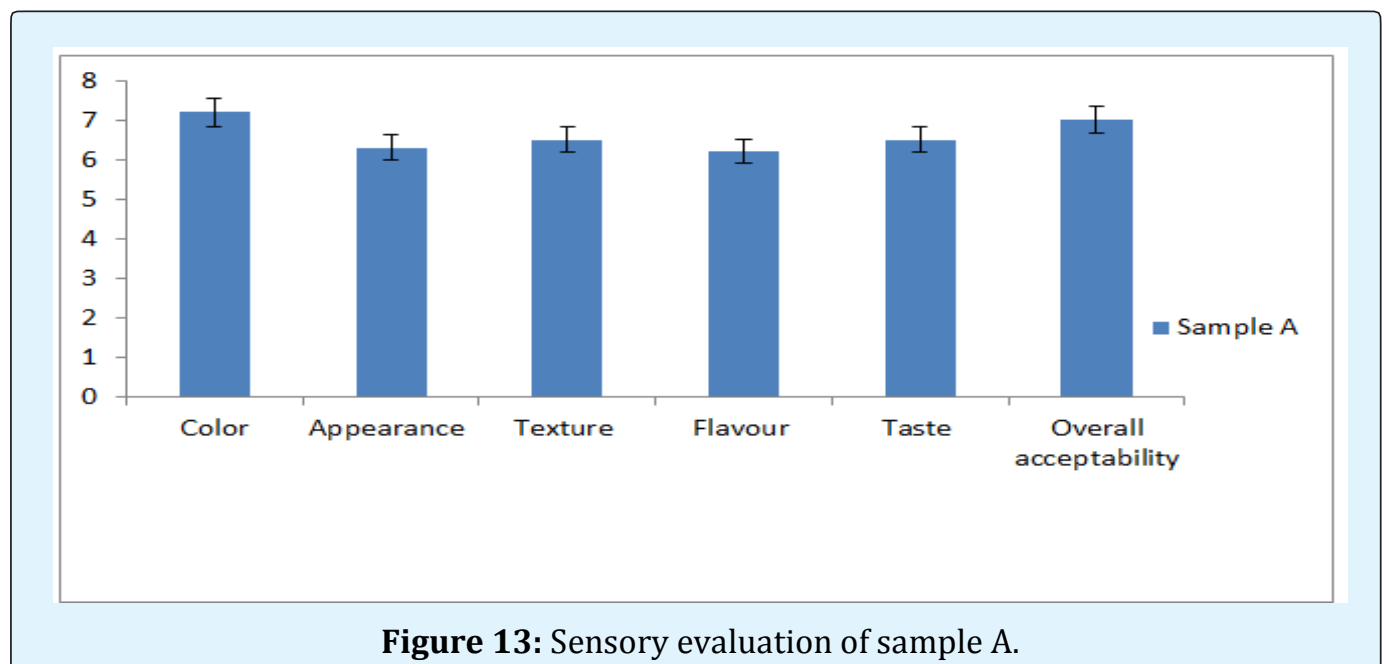

Figure 13: Sensory evaluation of sample A.

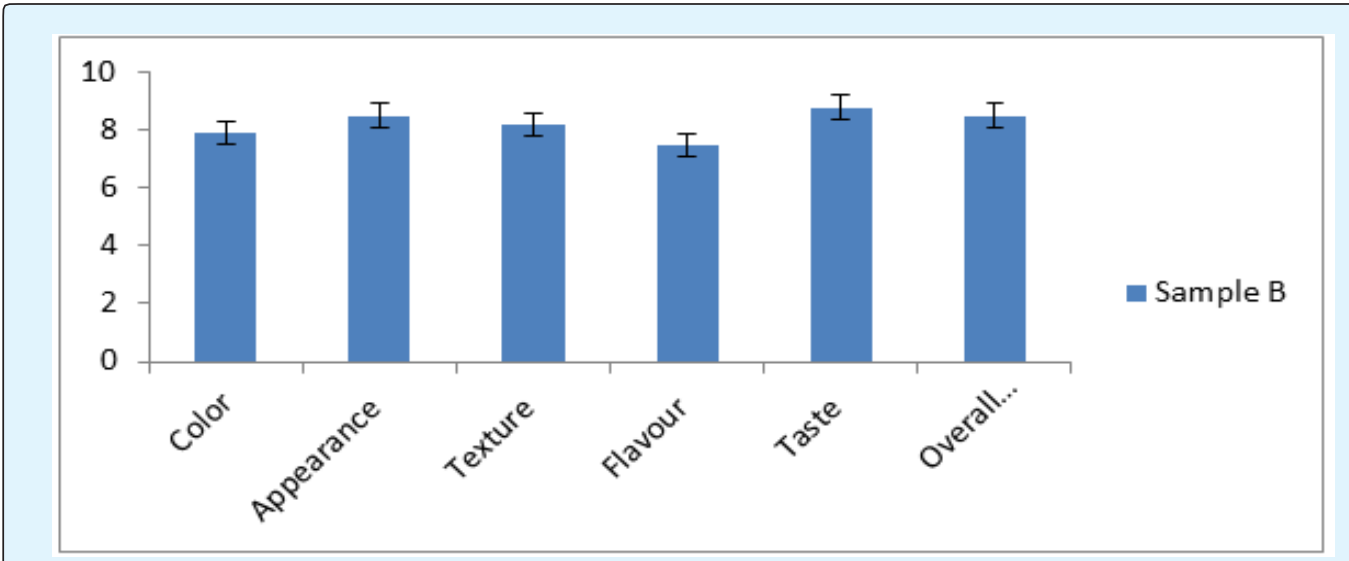

Figure 14: Sensory evaluation of sample B.

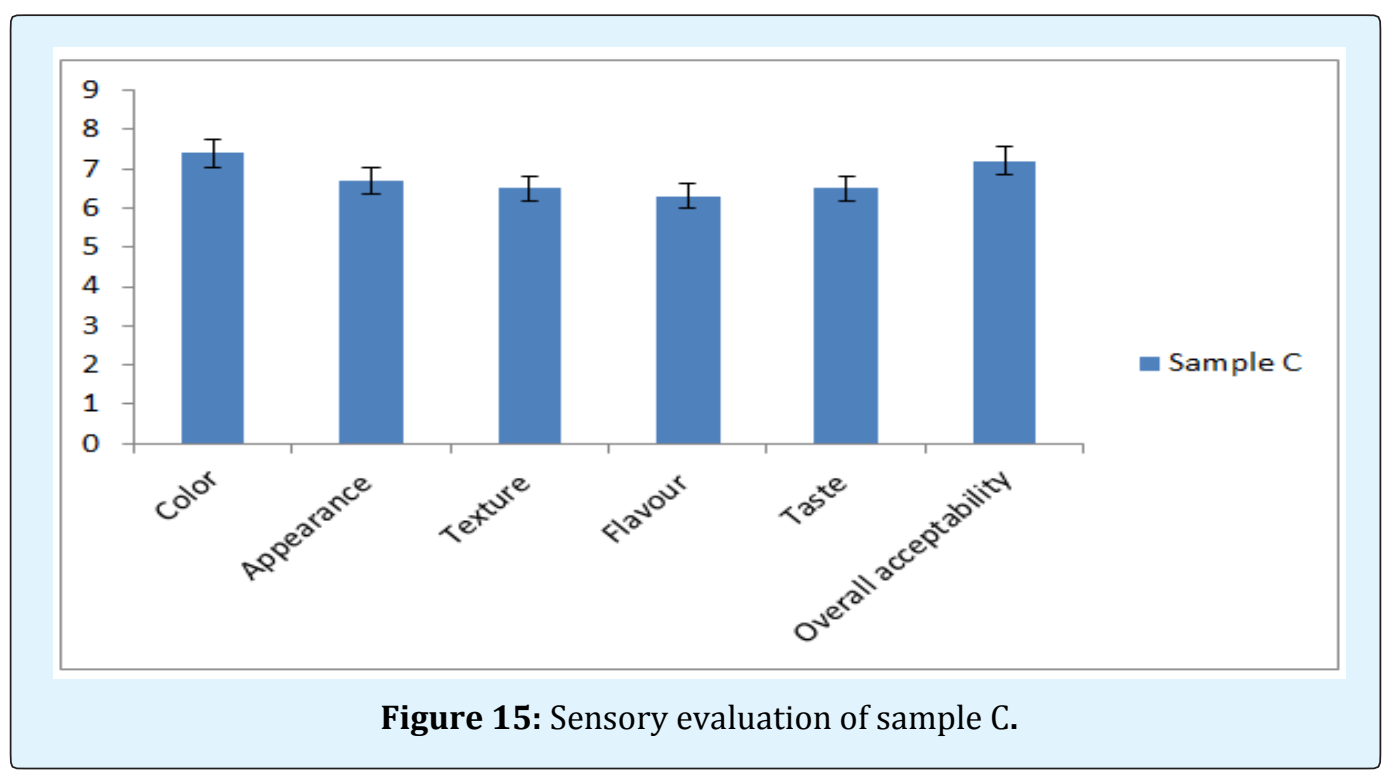




\section{Open Access Journal of Pharmaceutical Research}

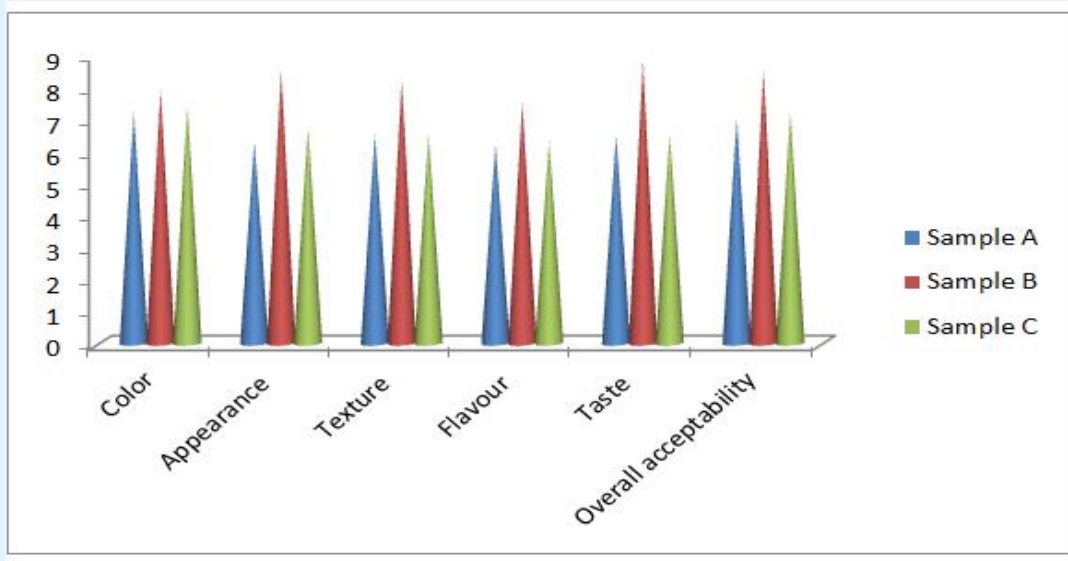

Figure 16: Sensory evaluation for combination of sample A, B and C.

\begin{tabular}{|c|c|c|c|c|c|c|}
\hline Sample & Color & Appearance & Texture & Flavour & Taste & Overall acceptability \\
\hline A & 7.2 & 6.3 & 6.5 & 6.2 & 6.5 & 7 \\
\hline B & 7.9 & 8.5 & 8.2 & 7.5 & 8.8 & 8.5 \\
\hline C & 7.4 & 6.7 & 6.5 & 6.3 & 6.5 & 7.2 \\
\hline
\end{tabular}

Table 3: Sensory evaluation of jelly.

By the evaluation of jellies by sensory evaluation like color appearance, texture, flavour, taste, overall acceptability for all prepared jellies. It is stored in a glass container. It can be concluded that the prepared jellies is to be nutritionally valuable due to the large amount of minerals and vitamins present in the fruit itself. So it has high nutritional value it is majorly accepted by the consumer.

\section{Conclusion}

In present research work attempt was made to formulate and evaluate natural jelly. It is prepared with carrot; beet root; papaya with different ratios. The maximum overall acceptability score for the fresh samples prepared with the ratio such as 25:20:50 for sample A.25:50:25 for sample B.50:25:20 for sample C. Evaluation studies were found such as highest moisture content is found in sample B and lowest in sample C. pH found to be highest in sample B and lowest in sample C. However, the minimum overall acceptability score of 8.5 (neither like nor dislike) was obtained to that sample which had carrot, beet root, papaya jelly after 60 days of storage at room temperature. The overall acceptability of mixed fruit jelly decreased with storage periods irrespective of storage condition. It can be concluded that the prepared jellies is to be nutritionally valuable due to the large amount of minerals and vitamins present in the fruit itself. So it has high nutritional value it is majorly accepted by the consumer.

\section{References}

1. Archer JS, Archer DF (2006) Oral contraceptive efficacy and antibiotic interaction: A myth debunked. J Am Acad Dermatol 46(6): 917-923.

2. Koul K, Jain P, Koul S, Charma K, Tikoo L, et al. (2009) Spray drying of beet root juice using different carriers. Indian J Chem Techno 9(5): 442-445.

3. Tavares Pereira AG, Pimenta Pereira PA, Borges SV, Dias MV, Figueiredo LP, et al, (2015) Physicochemical characterization and sensory evaluation of jellies made with guava peels (Psidium guajava L). Inter J Agril Policy Res 3 (11): 396-401.

4. Anand V, Kataria M, Kukkar V, Saharan V, Chowdhary PK (2007) The latest trends in the taste assessment of pharmaceuticals, Drug Discov Today 1205-6: 257265.

5. Jain S, Garg VK, Sharma P (2011) Anti-inflammatory activity of aqueous extract of Beta Vulgaris L. J basic clinic pharm 2 (2): 83-86. 


\section{Open Access Journal of Pharmaceutical Research}

6. Pinna M, Roberto S, Milia R, Marongiu E, Olla S, et al. (2014) Effect of Beet root juice supplementation on Aerobic response during swimming. Nutrients 6: 605615.

7. Abeer MNH, El-Dakak, Mona E, Youssef, Hanaa SM (2016) Evaluation of Beetroot Juice Blends with Carrot and Apple Juice as Healthy Beverage. Bulletin of the National Nutrition Institute of the Arab Republic of Egypt 48(100): 1-29.

8. Nakamura T, Tanigake A, Miyanaga Y, Ogawa T, Akiyoshi T, et al. (2002) The effect of various substances on the suppression of the bitterness of quinine-human gustatory sensation, binding, and taste sensor studies. Chem Pharm Bull 50(12): 15891593.

9. Laxman Kumar A, Madhumathi C, Syed S, Latha P (2017) Quality evaluation and storage study of papaya guava fruit bar. J Pharmacog Phytochemical 6(4): 2082-2087.
10. Srivastava R, Kumar S (2007) Fruits and Vegetables preservation- principles and practices, $3^{\text {rd }}$ (Edn.), International book distribution co, Army printing press Luck now, India.

11. Vidhya S, Narain A (2011) Formulation and Evaluation of Preserved Products Utilizing under Exploited Fruit, Wood Apple (Limonia acidissima). American-Eurasian J Agric Environ Sci 10(1): 112118.

12. Vali L, Stefanovits-Banyai E, Szentmihalyi K, Febel H, Sardi E, et al. (2007) Liver-protecting effects of table beet ( Beta vulgaris var Rubra) during ischemia reperfusion. Nutrition 23: 172- 178.

13. Singh Jay deep, Suresh Chandra (2012) Preparation and evaluation of guava-carrot jelly. Intl J Food Ferment Technol 2(2): 197-200. 